\title{
Income Poverty and Material Hardship among U.S. Women with Disabilities
}

\author{
Susan L. Parish \\ University of North Carolina at Chapel Hill \\ Roderick A. Rose \\ University of North Carolina at Chapel Hill \\ Megan E. Andrews \\ University of North Carolina at Chapel Hill
}

\begin{abstract}
This study analyzes the 2002 wave of the National Survey of America's Families to describe income poverty and material hardship among women with and without disabilities in the United States. Results suggest that women with disabilities experience such hardships as food insecurity, housing instability, inadequate health care, and loss of phone service at rates that are higher than those among nondisabled women. Rates of hardship remain higher even after adjusting for a host of individual characteristics, including marital status, age, race, and education. Although hardship declines as incomes rise for all women, those with disabilities show worse outcomes at every income level and experience substantial levels of hardship well into the middle and upper income ranges. The federal poverty level does not accurately capture women's experiences of material hardship, and these discrepancies are considerably worse among women with disabilities.
\end{abstract}

Women with disabilities are among the poorest adults in U.S. society (Haveman et al. 2000; Waldrop and Stern 2003). Although the specific underpinnings of this status have not been determined, some scholars speculate that it results from an intersection of gender-based and disability-based discrimination (Baldwin and Johnson 1995; O'Hara 2004). Regardless of the causes, these women have the lowest employment rates of any population subgroup, are more reliant on Supplemental Security Income (SSI; i.e., means-tested, disability-based income transfers) than

Social Service Review (March 2009).

(c) 2009 by The University of Chicago. All rights reserved.

0037-7961/2009/8301-0003\$10.00 


\section{Social Service Review}

any subgroup, and experience high costs of living due to their impairments. Relative to other subgroups, they are also less likely to marry. This in turn gives them less access to the resources of spouses. Further, because government benefit programs and private insurance typically do not cover all impairment-related expenses (U.S. General Accounting Office 1999), the costs of disablement are high in the United States.

The question raised by the evidence attesting to the high rates of income poverty among women with disabilities, by the high cost of living associated with their impairments, and by their reduced employment is, how are these women actually faring? The objective of this study is to consider the extent of material hardship among U.S. women with disabilities.

What remains unclear in the existing research is whether the federal poverty level (FPL), used by the U.S. government to determine eligibility for most welfare and health insurance benefits, adequately measures the extent of material hardship and deprivation among women with disabilities. That question is pursued here.

\section{Literature Review}

\section{Income Poverty in the United States}

The FPL refers to a set of income guidelines that reflect a household's pretax income and the number of individuals living in the household. Households with income below this level are deemed to be poor (USDHHS [U.S. Department of Health and Human Services] 2002). As originally implemented in 1963, the FPL was calculated by estimating the cost of a minimal food budget, tripling that estimate, and making adjustments for the size of the household as well as the age of the head of the household. The level was pegged to food costs because, in that era, food represented one-third of families' spending (Orshansky 1965). Since that time, the FPL has been adjusted annually for inflation, but it has not been wholly recalculated to reflect major changes in family spending patterns (Fisher 1992). Compared with U.S. families of the 1950 s, today's families spend a smaller proportion of their income on food and a greater proportion on housing, child care, and health care (Porter 1999). In addition, the FPL fails to account for regional variability in the cost of living, for the receipt of noncash benefits, and for the costs of necessities like child care, health care, and transportation. Therefore, many dispute the ability of this guideline to adequately identify those individuals whose basic needs are unmet (Renwick and Bergmann 1993; Citro and Michael 1995; Boushey et al. 2001; Blank 2008). 


\section{Material Hardship}

There is widespread agreement among the policy and research communities that income poverty does not provide a full picture of families' economic well-being. This is in part because such well-being is also affected by families' debt, assets, access to credit, and material hardship (Blank 2008). Material hardship research offers a way to directly measure families' living standards and their ability to meet basic needs. However, the study of material hardship is relatively new in poverty research. There is some disagreement over what constitutes true material need and what indicators are valid evidence of material hardship (Ouellette et al. 2004). Indeed, to fully understand the state of the research related to material hardship and how it is conceptualized and measured, a systematic evaluation was conducted by the assistant secretary for planning and evaluation of the U.S. Department of Health and Human Services (Ouellette et al. 2004).

In general, disagreement remains about how hardship should be conceptualized and measured. Frequently employed measures include food insecurity, housing instability, utility and telephone disconnection, and inadequate health care. Less frequently, researchers study neighborhood safety, adequacy of winter clothing, square footage of living space, and possession of a computer and other durable goods (Ouellette et al. 2004). Furthermore, there is no agreement on the validity of hardship indices, which often are summative indices that assign each item an ad hoc and typically equal weight. To date, researchers agree that more sophisticated and valid measurement approaches should be found (Ouellette et al. 2004). There is general agreement that studying hardship has utility, however, because hardship is a direct measure of families' financial well-being and illustrates the different facets of poverty that families experience (Ouellette et al. 2004).

Researchers primarily use four data sets in this body of research (Rose, Parish, and Yoo, forthcoming). Some analyze nationally representative samples from the Survey of Income and Program Participation (SIPP; e.g., Beverly 2001; Iceland and Bauman 2007) and the National Survey of America's Families (NSAF; e.g., Acs and Loprest 2001; Boushey et al. 2001: Parish et al. 2008; Rose et al., forthcoming). Others analyze local or regional samples primarily composed of welfare leavers or welfare populations, using the Women's Employment Survey (WES; Heflin 2006; Sullivan, Turner, and Danziger 2008) and the Child Support Demonstration Evaluation sample of welfare recipients in Wisconsin (Cancian and Meyer 2004).

\section{Relationship between Income Poverty and Material Hardship}

Few studies investigate the relationship between income poverty and material hardship. The earliest of these assesses hardship among a sam- 
ple of Chicago residents (Mayer and Jencks 1989) and finds a relatively low correlation. For example, income poverty accounts for just 14 percent of the variance in the number of hardships families experienced. Later research finds a similarly modest association between reports of material hardship and income poverty, but three particularly noteworthy studies evaluate the relationship over time. James Sullivan and his colleagues (2008) analyze the WES, a sample of current and former welfare recipients in a single Michigan county over the 1997-2003 period. They find that the prevalence of hardship declines as income poverty declines and that these declines are robust across measures of income poverty. Sullivan and his colleagues also find that having a mental health condition is a stronger predictor of material hardship than is income poverty.

Colleen Heflin (2006), using the same WES data set, examines the rates at which former and then-current welfare recipients reported experiencing hardship at any point over the 1997-2004 period. She finds that rates of reported material hardship are exceptionally high among these respondents, ranging between 48 and 56 percent, depending on the indicator of hardship. Of the sample, 48 percent reported experiencing housing problems at least once in their lives, and 56 percent reported having medical care problems at least once.

John Iceland and Kurt Bauman (2007) examine SIPP data to understand the dynamic relationship between income poverty and reports of material hardship over time. They find that although reported material hardship is most acute for those who experience deep poverty, even relatively short spells of income poverty are associated with material hardship. They also find that poverty has a greater effect on some specific types of hardship (e.g., food insecurity) than on others (i.e., neighborhood safety and housing problems). Their study clearly demonstrates the multidimensional nature of hardship and the complexities inherent in investigating it.

\section{Women with Disabilities and Poverty}

Women with disabilities compose approximately 18 percent of the population of U.S. women ages 16-64, and 43 percent of women older than 64 have disabilities (Waldrop and Stern 2003). The population of women with disabilities is heterogeneous because disabling conditions include sensory impairments (e.g., blindness and deafness), developmental disabilities (e.g., mental retardation and autism), mental illnesses, and mobility impairments (e.g., spinal cord injuries). Because of this considerable range of impairments, disabled women often differ considerably in their needs and experiences. For example, women with intellectual limitations or mental illnesses may need extensive support to 
make decisions and function in everyday living. Women with spinal cord injuries may only require devices that increase their mobility.

In the United States, women with disabilities are disproportionately represented among those living in poverty (Haveman et al. 2000; Waldrop and Stern 2003) and are consistently found to be among the most impoverished subgroups of the general population (Fujiura, Yamaki, and Czechowicz 1998). The reasons for the elevated poverty rates among women with disabilities are not well understood, but the increased vulnerability among these women is likely related to three factors: high costs of living with impairments, low rates of employment, and low rates of marriage (thus, they also often lack access to the resources of a wageearning spouse). Although having impairments clearly contributes to the likelihood of living in poverty, poverty also increases the risk of having disabilities. Being born in a poor family elevates the risk that a child will have impairments (Fujiura and Yamaki 2000; Emerson 2007). Such risk may stem from reduced access to adequate and appropriate health care (both prenatal care and care throughout childhood) as well as to sufficient nutrition. An array of environmental risks also accompanies poverty.

Women with disabilities face impairment-related living expenses not incurred by their nondisabled counterparts. They may have higher expenses for therapy, transportation, and health care. In addition, disabled women may incur expenses related to adapting the home environment and purchasing assistive technology. Public and private health insurance programs offer limited coverage of impairment-related expenses, so the burden of these costs falls on the women and their families.

Although the statistical data provided by previous efforts focus on the prevalence of poverty, they say little about more comprehensive measures of need. On balance, very few studies examine material hardship and deprivation among women with disabilities. Research also is limited on the relationship between income poverty and material hardship. This study therefore examines (1) the extent of material hardship for women with and without disabilities and (2) the relationship between income poverty and material hardship among U.S. women living with and without disabilities.

\section{Method}

Data Source

Data for this study come from the 2002 wave of the NSAF, a crosssectional telephone and area survey of approximately 42,000 U.S. households. The sample is nationally representative of the civilian, noninstitutionalized population of children and adults under age 65. It employs a stratified cluster design within which random sampling occurred (Safir, 
Scheuren, and Wang 2000). The NSAF used two distinct sampling procedures: a random-digit-dialed telephone survey of households with telephones and an area sample for households without telephones (Judkins et al. 2000). In the area sample, respondents in households without telephones were loaned cell phones for the telephone interviews. The area sample was used to ensure full population coverage because approximately 20 percent of poor families do not have working telephones in their homes (Giesbrecht, Kulp, and Starer 1996). The 2002 NSAF achieves national household response rates of 77.3 percent for the area sample and 53.2 percent for the random-digit-dialed sample (Brick et al. 2003).

Another strength of the NSAF for current purposes is that it oversamples minority populations, which are disproportionately represented among those living in poverty in the United States. Data collected for the NSAF include a range of factors and characteristics related to children and adults. These factors include health, economic well-being, and social well-being. Also included are demographic and socioeconomic data, as well as information related to material hardship (Safir et al. 2000).

Sample

All women ages 18-64 years in the NSAF are included in the study sample. ${ }^{1}$ The women's disability status is determined from the question, "Does the person have a physical, mental, or other health condition that limits the kind or amount of work she/you do?" Women who respond affirmatively are considered to have a disability; those who respond negatively are considered to be nondisabled. The present study sample includes 4,130 women with disabilities and 20,731 women identified as nondisabled. When weighted, the sample represents 13.3 million women with disabilities and 76.0 million nondisabled women.

The demographic characteristics of the sample are presented in table 1 along with tests of statistical significance for differences between the two groups. The two groups differ to a statistically significant degree on all descriptive characteristics except the number of dental visits. As compared with the nondisabled women, the women with disabilities are more likely to be black and single mothers. They have less education, lower household income, and smaller households. Women with disabilities in this sample also are older and are more likely to have visited a health care provider more than 2 times in the year prior to the survey.

Measures

Outcome measures. - Consistent with previous research, several binary measures describe whether a woman experiences material hardship, which is measured in four domains: food insecurity, housing instability, 
Table 1

Sample Description, U.S. Women with and without Disabilities, 2002

\begin{tabular}{|c|c|c|c|c|c|}
\hline & \multicolumn{2}{|c|}{$\begin{array}{l}\text { Disabled WOMEN } \\
\qquad(N=4,130)\end{array}$} & \multicolumn{2}{|c|}{$\begin{array}{c}\text { NONDISABLED } \\
\text { WOMEN } \\
(N=20,731) \\
\end{array}$} & \multirow{2}{*}{$\begin{array}{c}\text { Chi-SQUARED } \\
\text { Test } \\
\text { StaTistic }^{\mathrm{a}} \\
\text { (df) }\end{array}$} \\
\hline & $n$ & $\%$ & $n$ & $\%$ & \\
\hline Race or ethnicity: & & & & & $17.9 * * *(2)$ \\
\hline Black & 779 & 18.6 & 2,955 & 14.0 & \\
\hline White & 3,203 & 77.4 & 16,908 & 80.3 & \\
\hline Other & 148 & 4.0 & 868 & 5.7 & \\
\hline Education: & & & & & $160.2 * * *(3)$ \\
\hline No HS or GED & 836 & 20.8 & 2,187 & 10.8 & \\
\hline HS or GED, no college & 1,707 & 40.8 & 7,452 & 35.1 & \\
\hline Some college, no degree & 983 & 24.9 & 5,330 & 26.7 & \\
\hline BS or higher & 566 & 13.5 & 5,580 & 27.5 & \\
\hline Marital status: & & & & & $34.9 * * *(2)$ \\
\hline Single mothers & 2,049 & 44.6 & 7,585 & 35.5 & \\
\hline Cohabiting partners & 225 & 6.4 & 1,130 & 5.8 & \\
\hline Married partners & 1,856 & 49.0 & 12,016 & 58.7 & \\
\hline $\begin{array}{l}\text { No. of doctor visits in year } \\
\text { prior to survey: }\end{array}$ & & & & & $394.8^{* * *}(1)$ \\
\hline More than two & 2,752 & 66.1 & 7,001 & 35.1 & \\
\hline Two or fewer & 1,378 & 33.9 & 13,730 & 65.0 & \\
\hline $\begin{array}{l}\text { No. of dental visits in year } \\
\text { prior to survey: }\end{array}$ & & & & & $.94(1)$ \\
\hline More than two & 708 & 17.7 & 3,300 & 16.5 & \\
\hline Two or fewer & 3,342 & 82.3 & 17,431 & 83.5 & \\
\hline Income as $\%$ of FPL: & & & & & $190.4 * * *(3)$ \\
\hline $0 \%-99 \%$ & 1,248 & 23.0 & 2,627 & 9.8 & \\
\hline $100 \%-199 \%$ & 1,163 & 22.1 & 4,455 & 15.2 & \\
\hline $200 \%-299 \%$ & 649 & 15.9 & 3,740 & 17.2 & \\
\hline$\geq 300 \%$ & 1,070 & 39.1 & 9,909 & 57.8 & \\
\hline Mean age (years) & 44.6 & & 37.9 & & $16.9 * * *$ \\
\hline $\begin{array}{l}\text { Mean household size (adults } \\
\text { and children) }\end{array}$ & 2.9 & & 3.3 & & $9.9 * * *$ \\
\hline
\end{tabular}

NotE. - HS $=$ high school diploma; GED = general equivalency diploma; $\mathrm{BS}=$ bachelor's degree; FPL $=$ federal poverty level. The $2002 \mathrm{FPL}$ is $\$ 15,020$ for a household of three and $\$ 18,100$ for a household of four (USDHHS 2002).

${ }^{a}$ Chi-squared test of the null hypothesis of no group differences. In the case of age and household size, this is a $t$-test of the null hypothesis of no group differences.

$* * * \quad p<.001$.

loss of phone service, and inadequate health care. ${ }^{2}$ The analyses compare nine indicators of hardship. For all indicators, the reference period is the year prior to the survey. To assess food insecurity, respondents were asked whether they worried that food would run out, whether food bought did not last, whether they cut or skipped meals for lack of money, and whether they received emergency food. To measure housing instability, respondents were asked whether they were unable to pay rent or moved in with others. Respondents were also asked whether they experienced loss of phone service for more than 1 day in the year prior to the survey. The adequacy of respondents' health care access was 
assessed by two indicators. One asked whether, in the year prior to the survey, they postponed needed medical care, and the other asked whether they postponed needed dental care in the same period.

Income poverty measures. - The NSAF provides variables that describe household income relative to the federal poverty level. The U.S. FPL varies by the number of individuals living in a household and by the aggregate, pretax household income from all sources. The income poverty levels are constant across the United States, except for slight increases in Hawaii and Alaska (USDHHS 2002). For current purposes, women are stratified into four groups by their household's total income relative to the FPL: (1) less than 100 percent of the FPL (officially poor), (2) 100-199 percent of the FPL, (3) 200-299 percent of the FPL, and (4) 300 percent or more of the FPL. The 2002 FPL for a household of four was $\$ 18,100$ (USDHHS 2002); therefore, a woman living in a household of four with total income of $\$ 27,150$ is determined to be living at 150 percent of the FPL and is assigned to the second group. Household income in the NSAF includes earned income and income transfers (e.g., SSI and income from Temporary Assistance for Needy Families).

\section{Multivariate Analyses}

Because all dependent measures are binary, multivariate logistic regression is employed as the primary analytic strategy for answering both research questions (what is the extent of material hardship for women with disabilities and for those without them, and what is the relationship between income poverty and material hardship among those two groups of U.S. women?). The analyses are conducted in stages. First, analyses calculate rates at which women with disabilities and nondisabled women respectively report material hardships, and these rates are compared (see table 2). Second, logistic regression models are estimated for women with and without disabilities. These models predict hardship while controlling for household income, the woman's age, age squared, race, education level, marital status, and the number of people living in the household. In addition, given that women with disabilities typically have greater health care needs than nondisabled women, the models of health care postponement (i.e., postponement of needed medical and dental care) also control for the number of times the women report visiting a health care provider in the year prior to the survey. These covariates are included because women who have elevated health care needs will likely have more opportunities to delay care than those without elevated health needs. Odds ratios, 95 percent confidence intervals, and indicators of statistically significant group contrasts are presented in table 3 . 


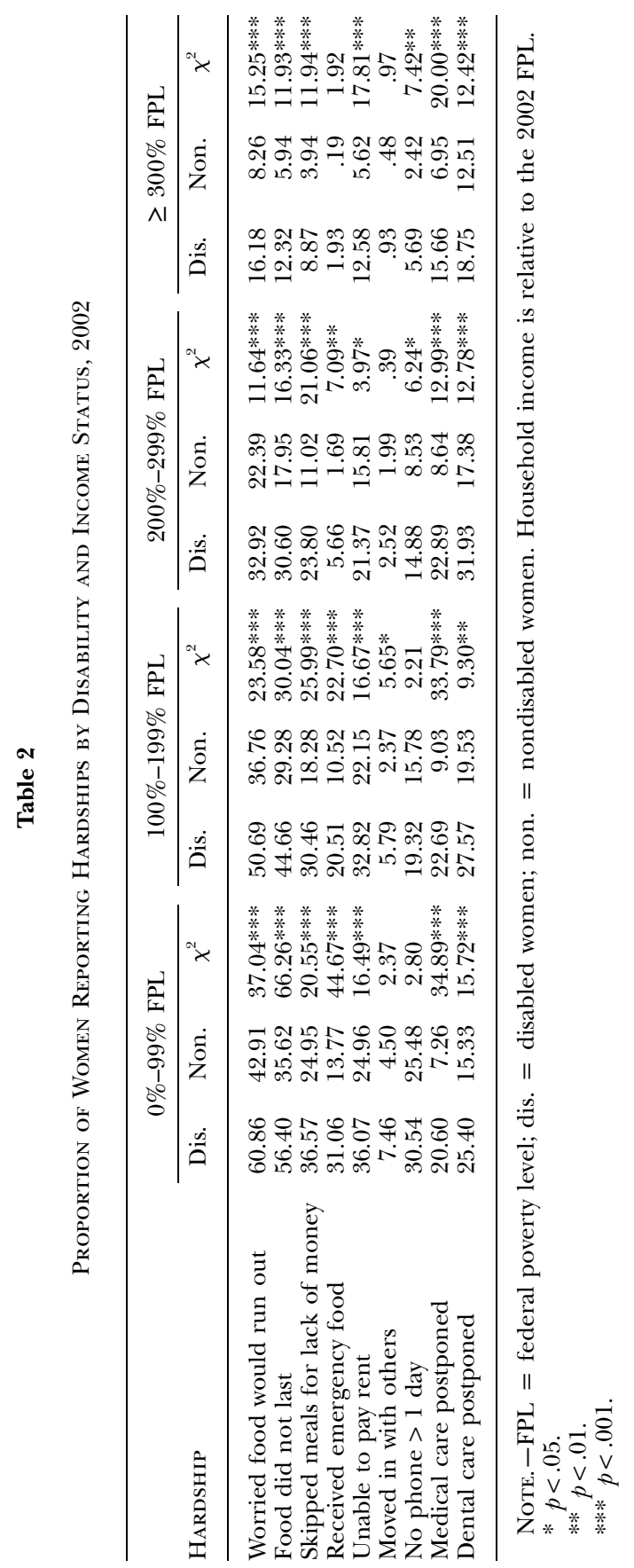




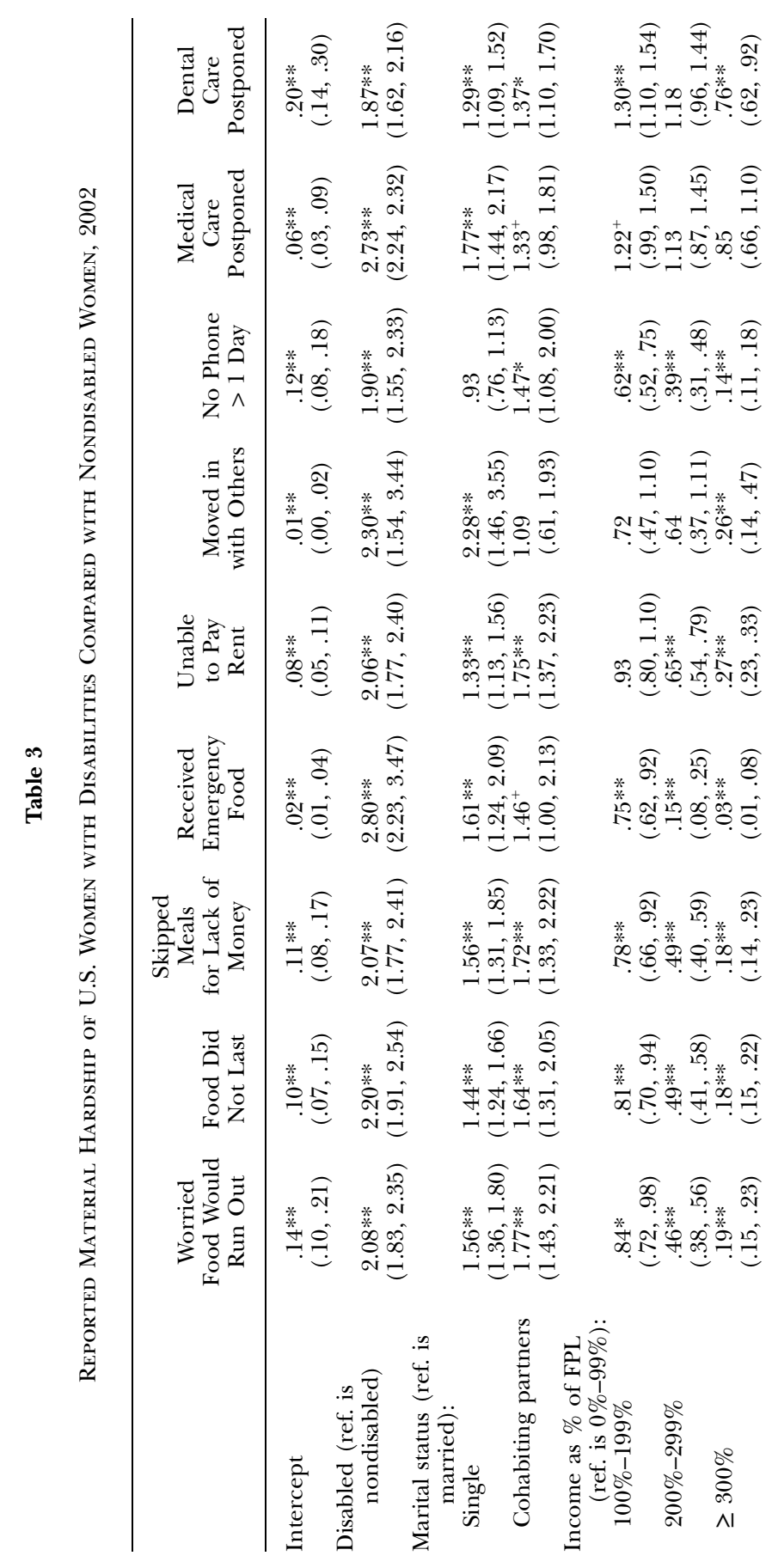




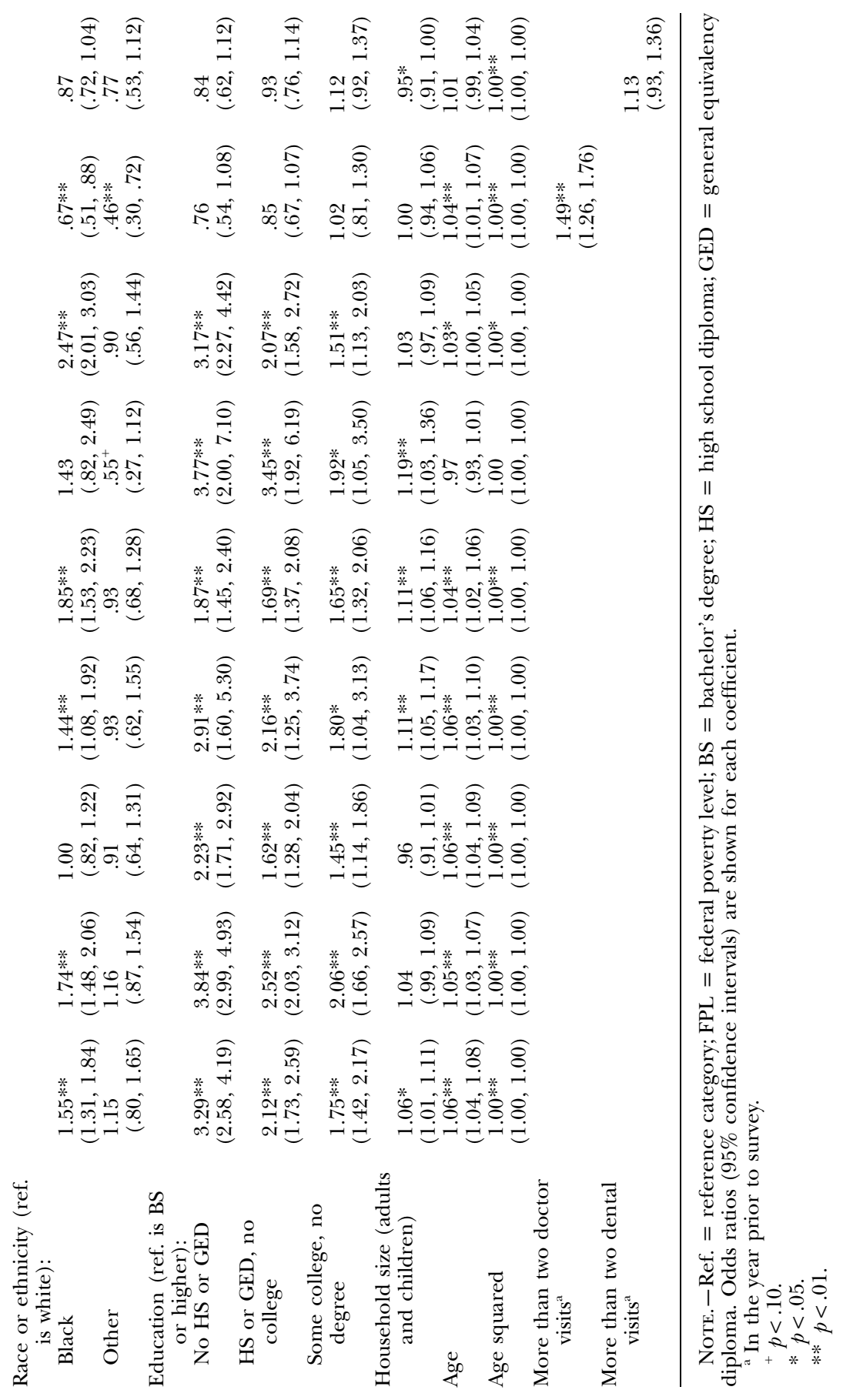


Stratified Sampling and Weighting

Because a stratified sample is analyzed, SUDAAN (version 8.0) is used to adjust standard errors and inferential statistic estimates. The SUDAAN program uses Taylor-series linearization to estimate variance with survey data derived from complex sampling designs such as those used in the NSAF (Safir et al. 2000; Research Triangle Institute 2001).

Data and the results presented here are weighted to reflect nonresponse, undercoverage, and each respondent's probability of selection, as well as the gender, age, and ethnic or racial distribution of the census estimates for the respondent. These results can be generalized to the noninstitutionalized civilian population of women ages 18-64 years living in the United States in 2002.

\section{Results}

The first research question concerns the rates of hardship among disabled and nondisabled U.S. women. The results relevant to this question are presented in table 2 . These results suggest that, at every income level, women with disabilities report statistically significantly higher rates of food insecurity (defined as a report that one was worried food would run out, that food did not last, that meals were skipped for lack of money, or that emergency food was received) and inadequate health care (defined as postponing needed medical or dental care). These rates of hardship vary. Among those in the lowest income group, 21 percent of women with disabilities report that they postponed needed medical care in the year prior to survey, and 61 percent of the women with disabilities in the same lowest income group worried that their supply of food would run out before funds were available to purchase more. Rates of reported food insecurity and inadequate health care continue to be high, even among women with disabilities in the highest income group. For example, 12 percent of women with disabilities who are in the highest income group report that food did not last, and 16 percent of women in the same group report postponing needed medical care.

Differences between the women with disabilities and those without them are mixed on indicators of housing instability and loss of phone. Across the income ranges, women with disabilities report being unable to pay rent at statistically significantly higher rates than nondisabled women, but only women with disabilities and incomes in the 100-199 percent FPL range are statistically significantly more likely to report moving in with others. On the measure of loss of phone service for more than 1 day, women with disabilities differ from those without disabilities to a statistically significant degree only in the two highest income ranges. Among those earning between 200 and 299 percent of 
the FPL, 15 percent of women with disabilities report that they lost phone service for more than 1 day in the year prior to the survey. In the highest income range, 6 percent of women with disabilities report this. By contrast, 9 percent of nondisabled women in the 200-299 percent range report losing phone service for more than 1 day, and 3 percent of nondisabled women in the highest income range report this.

Results in table 2 also shed light on the second research question, which involves the relationship between hardship and income poverty. The table shows that, for both groups of women, reported hardship rates generally decline as income increases, but rates are still relatively high at income levels well above the FPL. This trend is particularly true for women with disabilities. For example, 12 percent of women with disabilities and income in the highest range report that food did not last until they had money for more, and 13 percent report being unable to pay rent at some time in the year prior to survey. Furthermore, the rates at which women with disabilities postpone needed medical and dental care do not decline until their income reaches or exceeds 300 percent of the FPL.

Table 3 presents the results of logistic regression models for each of the nine measures of material hardship. The models control for the woman's race, education level, marital status, age, age squared, and the number of individuals living in the household.

The multivariate analyses presented in table 3 control for covariates that are associated with poverty and deprivation. These analyses indicate that the results reported in table 2 are robust. Net of these covariates, having a disability has a clear relationship to the likelihood that a woman will experience each of the nine measures of hardship. Women with disabilities fare substantially worse than nondisabled women on all nine measures of material hardship. Women with disabilities are more likely than nondisabled women to report food insecurity in the year prior to the survey. They are more than twice as likely as members of the comparison group to report that they worried food would run out, the food they bought did not last, they cut or skipped meals for lack of money, or they received emergency food in the 12 months prior to the survey. The odds ratios range from 2.07 to $2.80(p<.01)$ for all four indicators.

Housing instability is also a problem among sample members. Women with disabilities are more than twice as likely as nondisabled women to report being unable to pay their rent in the year prior to survey $(\mathrm{OR}=2.06, p<.01)$ or to report moving in with others over that period $(\mathrm{OR}=2.30, p<.01)$. Women with disabilities are nearly twice as likely to report that they lost phone service for more than 1 day in the year prior to survey $(\mathrm{OR}=1.90, p<.01)$.

Finally, women with disabilities have markedly worse rates of receiving care when it is needed. As compared with their nondisabled counterparts, women with disabilities are nearly three times more likely to post- 


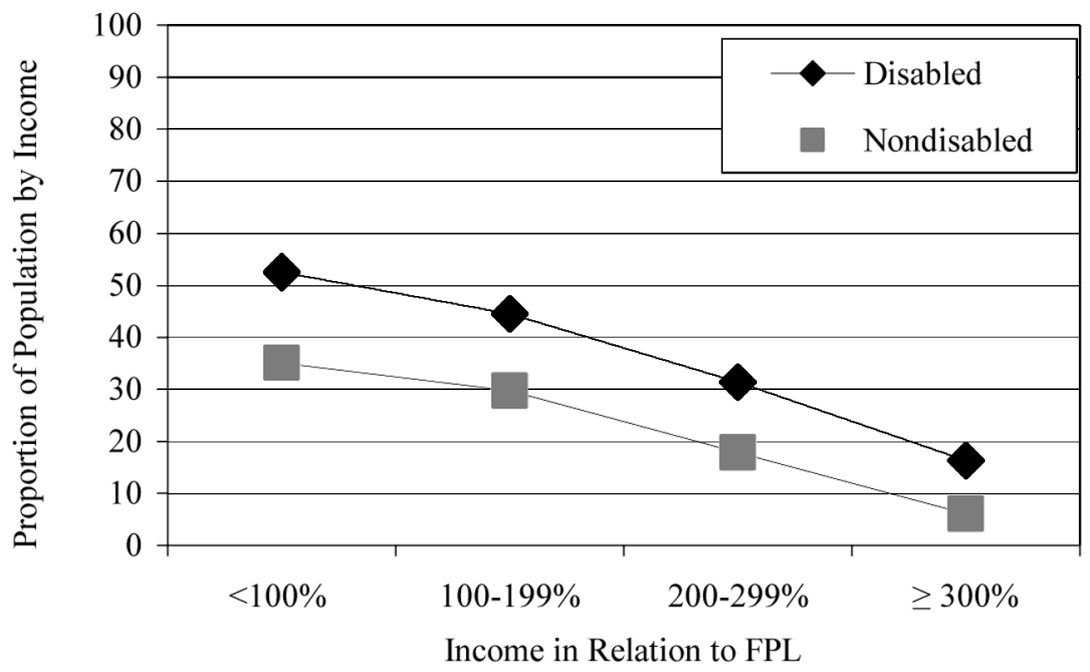

FIG. 1.-Percentage of U.S. women with and without disabilities reporting hardship in two or more domains, by income level, 2002. NotE.-FPL $=$ federal poverty level.

pone medical care during the year prior to survey $(\mathrm{OR}=2.73, p<.01)$ and nearly twice as likely to report postponing dental care $(\mathrm{OR}=1.87$, $p<.01)$.

The second research question concerns the relationship between material hardship and income poverty. Figure 1 further illustrates findings related to this question, reporting the percentage of women with hardship in two or more of the four hardship domains (i.e., food insecurity, housing instability, loss of phone service, and inadequate health care). Results are stratified by income group. The lines in each figure represent distributions within each income level relative to the FPL. Each point along the line represents the percentage of women in that income level who report more than one hardship domain.

Figure 1 further illustrates the relationship identified in table 2; although the proportion experiencing hardship in two or more domains decreases for both groups (women with and without disabilities) as income increases, hardship persists in the two highest income ranges. Fully 31 percent of women with disabilities and income in the 200-299 percent FPL range experience hardship in two or more domains, and 16 percent of those with incomes at or above 300 percent of the FPL experience hardship in two or more domains. Rates for nondisabled women are consistently lower across income ranges than those for the women with disabilities.

Figure 2 illustrates the mean number of hardships by response group, and results are stratified by income. This arrangement offers another way of understanding the relationship between income and hardship 


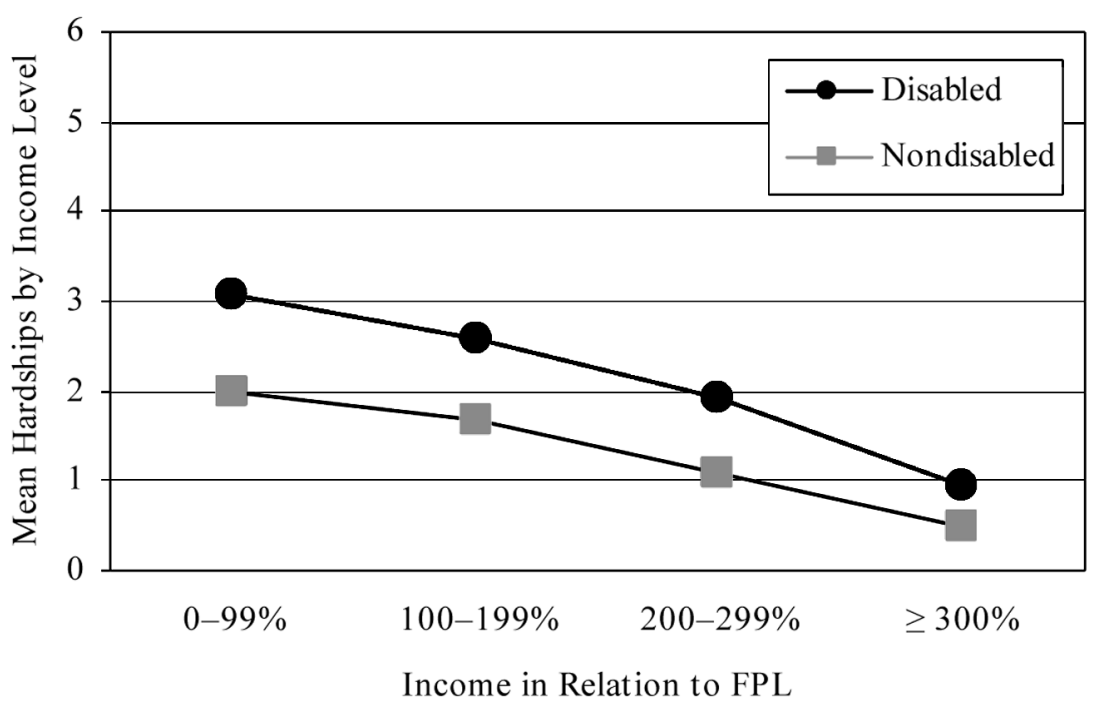

FIG. 2.-Mean number of hardships reported by U.S. women with and without disabilities, 2002. Note.-FPL $=$ federal poverty level.

among these groups of women. Figure 2 indicates that the mean number of reported hardships, not surprisingly, is highest among women with incomes lower than 100 percent of the FPL. Hardship is found to decline as income increases. However, the mean number of hardships is statistically significantly higher for women with disabilities than for nondisabled women, and this finding persists across income ranges. Most compelling, however, is that women with disabilities in the two highest income ranges still experience hardship. On average, those with incomes between 200 and 299 percent of FPL experience two hardships. Those with incomes at or above 300 percent of the FPL experience one. Thus, rates of deprivation are high even among women with disabilities whose household income is well above the FPL.

It is notable that there is a high prevalence of reported hardships among women with disabilities whose income is greater than 200 percent of the FPL. In 2002, income of twice the FPL represented $\$ 36,200$ for a household of four (USDHHS 2002).

\section{Discussion and Conclusions}

This study is the first nationally representative inquiry into material hardship experienced by U.S. women with disabilities. An important strength is its reliance on a national probability sample that includes households without telephones, as such households comprise a substantial subset of the poor typically excluded from national surveys. 
Among the sample population, the women with disabilities are found to endure markedly greater levels of reported material hardship than nondisabled women do. Regardless of income level, women with disabilities are at substantially elevated risk for deprivation. Although this risk declines as household income increases, a substantial proportion of middle-class women with disabilities report material hardship.

These findings specifically call into question the utility of continued use of the FPL to set eligibility for social welfare and, specifically, for disability services. Women with disabilities, even those with incomes well beyond levels officially considered poor, report experiencing hardship and deprivation at high rates. As such, social welfare programs that use the FPL to determine eligibility may not account for the effect of disability on material hardship. Furthermore, these findings seem to indicate that public resources are not being efficiently deployed to meet the needs of those who are most vulnerable to hardship. Findings are consistent with previous research in which hardship is found to decline as income increases (e.g., Beverly 2001), to increase as poverty deepens (e.g., Iceland and Bauman 2007), and to occur at low rates among nondisabled women at the highest income levels (Beverly 2001).

Iceland and Bauman (2007) find that the relationship between poverty and material hardship depends in part on the specific indicator of hardship, and food insecurity is found to be most strongly associated with income poverty. The current findings are somewhat consistent with theirs: food insecurity is the most prevalent form of hardship reported by poor women with disabilities. Rates of moving in with others are least associated with income poverty, but rates of inadequate medical care (i.e., postponement of medical or dental care) are essentially the same for women with disabilities in the three lowest tiers of income. However, most forms of reported hardship persist into the sample's upper income ranges.

\section{Limitations and Future Research Directions}

Further research is warranted to address five limitations of the present study. First, causal inferences cannot be ascertained from these crosssectional data. This study is descriptive. Future research with longitudinal data is warranted to understand the dynamic nature of material hardship in the lives of women with disabilities.

Second, it is not possible with the data on hand to ascertain the severity of the women's impairments or to analyze the effects that severity may have on material well-being. It is likely that the elevated costs associated with women's impairments are highest among women with the most severe conditions, as such an association is found among children with disabilities (e.g., Kuhlthau et al. 2005; Shattuck and Parish 2008). However, the NSAF did not collect data on impairment, and therefore this 
issue could not be analyzed. Further research in this area would aid policy makers and practitioners by providing a comprehensive understanding of the links between challenges faced by women and the severity of their conditions.

A third limitation is the likely underreporting of disability within the sample. In the NSAF, a gross measure defines impairment as a condition that limits employment. Although this definition is commonly employed in survey research (e.g., SIPP) and federal income transfer programs (e.g., SSI and Social Security Disability Insurance) in the United States, the adoption of a more nuanced definition in future research would help to better capture the specific experiences of these women.

Fourth, this research does not examine material hardship among men with disabilities, a topic that future researchers should consider. It focuses on the experiences of women with disabilities largely because they are more financially vulnerable than men with disabilities or nondisabled women (e.g., Haveman et al. 2000). Also, there are important gender-based differences in the incidence of disability, in the prevalence of disability, in the age of the population with disabilities, and in takeup rates for disability-based income transfers (i.e., SSI and Social Security Disability Insurance). These differences require complicated analyses beyond the scope of the current study and the capacity of the NSAF data set.

A final consideration is that these data are drawn from self-reports of material hardship. It is possible that they are biased. However, no reason or previous research evidence supports the assumption that reporting bias would be higher among women with disabilities than among nondisabled women. As such, any bias is likely to be randomly distributed across the entire sample and is unlikely to influence the direction of the findings reported here.

Another important direction for future research is to examine the role of disability and welfare programs in mitigating the hardship borne by women with disabilities. A number of current programs (e.g., SSI and Medicaid) support women with disabilities. Understanding how these programs reduce material deprivation or fail to do so is an important objective for future investigation; however, such inquiry is beyond the scope of the current analyses.

Future research could also fruitfully attempt to understand the specific ways in which material hardship is manifested in the lives of women with disabilities. For example, Medicaid protects some low-income women with disabilities by providing them with health care access. Extending the present inquiry to examine how hardship is related to receipt of social welfare benefits would inform policy makers about how public resources could most efficiently address women's real needs. Although such an analysis is beyond the scope of the present study, future research in this area will be important to policy makers, advocates, 
and practitioners interested in improving the well-being of women with disabilities.

\section{Implications and Conclusions}

This article makes two new and essential contributions to the research literature. First, women with disabilities are found to be substantially more likely to live in conditions of hardship and deprivation than are nondisabled women. A disturbing proportion of women with disabilities experience material hardship and deprivation. Second, women with disabilities are found to experience relatively high rates of deprivation at the highest income level. This finding is at odds with previous population-based research. For instance, Sondra Beverly (2001) finds that less than 3 percent of the population with income at or above 300 percent of the FPL reported any hardship at all. The FPL does not appear to capture the experiences of poverty or deprivation among women with disabilities.

Findings from this study highlight two crucial limitations in current federal policy. First, the current federal poverty guidelines fail to accurately represent the full magnitude of deprivation in the United States. In addition, results from these analyses suggest that current social welfare policies are either not reaching the target population or are not fulfilling their intended goals. This shortfall is suggested by the extreme rates of hardship (46 percent among women with disabilities and 34 percent among nondisabled women) reported by all women living below the poverty line, a population explicitly targeted by supportive social services. Such deficits in the FPL and the implementation of assistance programs are consistent with the findings of previous research. These deficits also underlie previous recommendations for the development of a comprehensive understanding of poverty and family outcomes. Such an understanding could better inform policy makers in developing responsive, effective policies (see, e.g., Citro and Michael 1995).

The FPL is used to determine eligibility for most government programs that provide income, health, food, and disability-related benefits. However, the FPL is not accurately capturing the range of women who experience material hardship and who could potentially benefit from these programs. At a minimum, policy makers should consider adjusting the FPL standards for social welfare programs that serve women with disabilities. They should also consider the unique needs of women with disabilities in reconfiguring social welfare programs and creating new ones.

Alternative analyses, particularly those examining families' financial well-being and experience of material hardship, may be particularly useful in understanding the complex poverty experiences of women with disabilities. The current study presents such an analysis. This line 
of inquiry is also likely to be valuable because it reveals another dimension in the potential role that policy can play in improving people's lives.

\section{References}

Acs, Gregory, and Pamela Loprest. 2001. "Final Synthesis Report of Findings from ASPE's 'Leavers' Grant." Report to the U.S. Department of Health and Human Services (contract no. HHS-100-99-0003). Urban Institute, Washington, DC.

Baldwin, Majorie L., and William G. Johnson. 1995. "Labor Market Discrimination against Women with Disabilities." Industrial Relations 34 (4): 555-77.

Beverly, Sondra G. 2001. "Material Hardship in the United States: Evidence from the Survey of Income and Program Participation." Social Work Research 25 (3): 143-51.

Blank, Rebecca M. 2008. "Presidential Address: How to Improve Poverty Measurement in the United States." Journal of Policy Analysis and Management 27 (2): 233-54.

Boushey, Heather, Chauna Brocht, Bethney Gundersen, and Jared Bernstein. 2001. Hardships in America: The Real Story of Working Families. Washington, DC: Economic Policy Institute.

Brick, J. Michael, David Ferraro, Teresa Strickler, and Carin Rauch. 2003. "2002 NSAF Response Rates." NSAF Methodology Report no. 8. Urban Institute, Washington, DC. http://www.urban.org/UploadedPDF/900692_2002_Methodology_8.pdf.

Cancian, Maria, and Daniel R. Meyer. 2004. "Alternative Measures of Economic Success among TANF Participants: Avoiding Poverty, Hardship, and Dependence on Public Assistance." Journal of Policy Analysis and Management 23 (3): 531-48.

Citro, Constance F., and Robert T. Michael. 1995. Measuring Poverty: A New Approach. Washington, DC: National Academy Press.

Emerson, Eric. 2007. "Poverty and People with Intellectual Disabilities." Mental Retardation and Developmental Disabilities Research Reviews 13 (2): 107-13.

Fisher, Gordon. 1992. "The Development and History of the Poverty Thresholds." Social Security Bulletin 55 (4): 3-14.

Fujiura, Glenn T., and Kiyoshi Yamaki. 2000. "Trends in Demography of Childhood Poverty and Disability." Exceptional Children 66 (2): 187-99.

Fujiura, Glenn T., Kiyoshi Yamaki, and Susan Czechowicz. 1998. "Disability among Ethnic and Racial Minorities in the United States: A Summary of Economic Status and Family Structure." Journal of Disability Policy Studies 9 (2): 111-30.

Giesbrecht, Lee H., Dale W. Kulp, and Amy W. Starer. 1996. "Estimating Coverage Bias in RDD Samples with Current Population Survey Data." 503-8 in Proceedings of the Survey Research Methods. Washington, DC: American Statistical Association.

Haveman, Robert, Karen Holden, Barbara Wolfe, Paul Smith, and Kathryn Wilson. 2000. "The Changing Economic Status of Disabled Women, 1982-1991." 51-80 in The Economics of Disability, edited by David S. Salkever, Alan L. Sorkin, and Susan L. Ettner. Stamford, CT: JAI Press.

Heflin, Colleen M. 2006. "Dynamics of Material Hardship in the Women's Employment Study." Social Service Review 80 (3): 377-97.

Iceland, John, and Kurt J. Bauman. 2007. "Income Poverty and Material Hardship: How Strong Is the Association?" Journal of Socio-Economics 36 (3): 376-96.

Judkins, D., J. Michael Brick, Pam Broene, David Ferraro, and Teresa Strickler. 2000. "1999 NSAF Sample Design.” NSAF Methodology Report no. 2. Urban Institute, Washington, DC.

Kuhlthau, Karen, Kristen Smith Hill, Recai Yucel, and James M. Perrin. 2005. "Financial Burden for Families of Children with Special Health Care Needs." Maternal and Child Health Journal 9 (2): 207-18.

Mayer, Susan E., and Christopher Jencks. 1989. "Growing Up in Poor Neighborhoods: How Much Does It Matter?” Science 243 (4897): 63-81.

O'Hara, Brett. 2004. "Twice Penalized: Employment Discrimination against Women with Disabilities." Journal of Disability Policy Studies 15 (1): 27-34.

Orshansky, Mollie. 1965. "Counting the Poor: Another Look at the Poverty Profile." Social Security Bulletin 28 (1): 3-29. 
Ouellette, Tammy, Nancy Burstein, David Long, and Erick Beecroft. 2004. Measures of Material Hardship: Final Report. Report (contract no. 282-98-006, task order 31). Washington, DC: U.S. Department of Health and Human Services, Office of the Assistant Secretary for Planning and Evaluation.

Parish, Susan L., Roderick A. Rose, Michal Grinstein-Weiss, Erica L. Richman, and Megan E. Andrews. 2008. "Material Hardship in U.S. Families Raising Children with Disabilities." Exceptional Children 75 (1): 71-92.

Porter, Kathryn. 1999. "Proposed Changes in the Official Measure of Poverty." Report no. 99-000, November 15. Center on Budget and Policy Priorities, Washington, DC. http://www.cbpp.org/11-15-99wel.htm.

Renwick, Trudi J., and Barbara R. Bergmann. 1993. "A Budget-Based Definition of Poverty: With an Application to Single-Parent Families." Journal of Human Resources 28 (1): $1-24$.

Research Triangle Institute. 2001. SUDAAN User's Manual, Release 8.0. Research Triangle Park, NC: Research Triangle Institute.

Rose, Roderick A., Susan L. Parish, and Joan P. Yoo. Forthcoming. "Measuring Material Hardship among the U.S. Population of Women with Disabilities Using Latent Class Analysis." Social Indicators Research.

Safir, Adam, Fritz Scheuren, and Kevin Wang. 2000. "Survey Methods and Data Reliability, 1997 and 1999." Report, November 3. Urban Institute, Washington, DC.

Shattuck, Paul T., and Susan L. Parish. 2008. "Financial Burden in Families of Children with Special Health Care Needs: Variability among States." Pediatrics 122 (1): 13-18.

Sullivan, James X., Lesley Turner, and Sheldon H. Danziger. 2008. "The Relationship between Income and Material Hardship." Journal of Policy Analysis and Management 27 (1): 63-81.

USDHHS (U.S. Department of Health and Human Services), Office of the Secretary. 2002. "Annual Update of the HHS Poverty Guidelines." Federal Register 67, no. 31 (February 14): 6931-33.

U.S. General Accounting Office. 1999. SSI Children: Multiple Factors Affect Families' Costs for Disability-Related Services. Report no. GAO/HEHS-99-99 to Congressional Committees. Washington, DC: U.S. General Accounting Office.

Waldrop, Judith, and Sharon M. Stern. 2003. "Disability Status: 2000." Census 2000 Brief no. C2KBR-17, March. U.S. Census Bureau, Washington, DC. http://www.census.gov/ prod/2003pubs/c2kbr-17.pdf.

\section{Notes}

The authors appreciate the comments of Diane Wyant on an earlier version of this manuscript and would like to acknowledge funding support to the first author from the Center on Poverty, Work and Opportunity at the University of North Carolina at Chapel Hill.

1. The 2002 NSAF sample includes 25 women for whom a weighted variable is missing or nonpositive. The women are excluded from these analyses.

2. The loss of phone service measure was coded from responses to multiple questions. 